\title{
Correction to: Optimal control analysis of COVID-19 vaccine epidemic model:
}

\section{a case study}

\section{Arshad Alam Khan, Saif Ullah ${ }^{\mathrm{a}} \mathbb{D}$, Rohul Amin}

Department of Mathematics, University of Peshawar, Khyber Pakhtunkhwa, Pakistan

(C) The Author(s), under exclusive licence to Società Italiana di Fisica and Springer-Verlag GmbH Germany, part of Springer Nature 2022

Correction to: Eur. Phys. J. Plus (2022) 137:156

https://doi.org/10.1140/epjp/s13360-022-02365-8

In this article the affiliation details were incorrectly given as 'Department of Mathematics, University of Peshawar, Khyber Peshawar, Pakistan' but should have been 'Department of Mathematics, University of Peshawar, Khyber Pakhtunkhwa, Pakistan'.

The original article can be found online at https://doi.org/10.1140/epjp/s13360-022-02365-8.

a e-mail: saifullah.maths@uop.edu.pk (corresponding author) 